\title{
Measuring ICT use and contributing conditions in primary schools
}

\section{Ruben Vanderlinde, Koen Aesaert and Johan van Braak}

Ruben Vanderlinde is a Tenure Track Professor at the Department of Educational Studies, Ghent University, Belgium. His research interests are in the field of educational innovation, teacher training and professionalisation, and the integration of Information and Communication Technologies (ICT) in education. Koen Aesaert is a Teaching and Research Assistant at the Department of Educational Studies, Ghent University in Ghent, Belgium. His research interests concern the assessment of 21st century skills and ICT competences. Johan van Braak is Professor at the Department of Educational Studies, Ghent University, Belgium. He coordinates the research group "Innovation in Compulsory Education." Address for correspondence: Mr Ruben Vanderlinde, Ghent University, Department of Educational Studies, Henri Dunantlaan 2, Ghent B9000, Belgium. Email: ruben.vanderlinde@ugent.be

\begin{abstract}
Information and communication technology (ICT) use became of major importance for primary schools across the world as ICT has the potential to foster teaching and learning processes. ICT use is therefore a central measurement concept (dependent variable) in many ICT integration studies. This data paper presents two datasets (2008 and 2011) that contain measurements on ICT use in primary schools on the one hand and contributing conditions on the other hand. In both datasets, ICT use refers to different types of use: basic ICT use, ICT as a learning tool and ICT as an information tool. The influencing conditions refer to variables situated on the individual teacher level (eg, ICT competences, ICT professional development, etc) and the school organization level (eg, ICT school vision, ICT leadership, etc) that support or hinder the use of ICT for teaching and learning.
\end{abstract}

\section{Introduction}

Nowadays, it is widely accepted that information and communication technology (ICT) plays a central and significant role in the educational, economic and social changes that characterize the current knowledge society (Kozma, 2008). The so-called 21st century skills including communication, creativity and ICT use gain importance in educational curricula (Voogt \& Pareja Roblin, 2012). In order to cope with these changes, pupils must master different skills and attitudes; teachers and schools are making use of ICT in their practices to improve pupils' and students' "twenty-first century skills" (Anderson, 2008). ICT integration for teaching and learning has thus become a major task for primary schools all around the world (Vanderlinde, van Braak \& Hermans, 2009). In parallel, research on ICT integration has become an important research topic in the broad research field of educational technology. Research on ICT integration in education is a diverse domain characterized by different goals, questions, assumptions, research designs and methods of data collection and analysis (Evers, Sinnaeve, Clarebout, van Braak \& Elen, 2009; Marshall \& Cox, 2008). Roughly, the ICT integration research community can be divided into three streams (Evers et al, 2009): (1) researchers investigating the effects of ICT on pupils' and students' performance and learning, (2) researchers investigating the qualitative use of ICT in educational settings and (3) researchers looking for conditions that support the use of ICT for teaching and learning. This challenge refers to barriers and strategies (Hew \& Brush, 2007) influencing ICT integration. Underlying these three streams is a (4) fourth research challenge (Vanderlinde, Aesaert \& van Braak, 2014) for ICT integration researchers to tackle the methodological question 
of how to conceptualize and measure ICT integration and ICT use in education in a valid and reliable way. Although ICT use has been measured and operationalized in many different quantitative and qualitative ways (de Koster, Kuiper \& Volman, 2012), nowadays, researchers reach consensus that ICT use should be considered as complex and multilayered instead of a monolithic phenomenon.

This data paper presents two datasets (one collected in 2008 and one in 2011) that contain cross-sectional measurements of ICT use in primary schools. The assumptions underlying the development of the datasets and their accompanying research questions connect to the third and fourth research stream mentioned above. The search for conditions-situated on different levels - that best support the use of ICT for teaching and learning on the one hand (third stream), and the question of how to validly and reliably conceptualize and measure ICT use on the other hand (fourth stream). This means that both datasets contain (1) variables that refer to influencing individual teacher-level conditions and school organizational conditions (see Figure 1 and Table 1) and (2) variables that measure ICT use. In both datasets, ICT use is conceived as the combination of different types of use: basic ICT skills, ICT as a learning tool and ICT as an information tool (Tondeur, van Braak \& Valcke, 2007; Vanderlinde \& van Braak, 2010).

\section{Research background}

The two datasets presented in this data paper were collected in Flanders, the Dutch-speaking part of Belgium. This contextual background is a necessary information because since 2007, the Flemish government has administered a compulsory ICT curriculum to primary schools. The ICT curriculum is written in terms of ICT attainment targets or minimum objectives, which describe the ICT knowledge, skills and attitudes viewed by the government as necessary and attainable by most students by the end of compulsory education. The ICT attainment targets do not focus on technical skills, but emphasize the integrated use of ICT within the teaching and learning process (Aesaert, Vanderlinde, Tondeur \& van Braak, 2013; Vanderlinde et al, 2009). The Flemish government expects that schools implement the ICT curriculum into practice and translate the broadly formulated ICT attainment targets into concrete teaching and learning activities. Within this context, data have been collected to get a rich understanding of ICT use in Flemish primary schools. More concretely, dataset 1 was collected in 2008, just 1 year after the formulation and administration of the ICT curriculum. Dataset 2 was collected in 2011 and was considered as a follow-up of dataset 1. From a school improvement perspective (Hopkins, 2001), this means that dataset 1 was collected in the "initiation" phase of the ICT curriculum, while dataset 2 was collected between the "implementation" and "institutionalization" phase.

\section{Details of the dataset}

Both datasets were administered to primary school teachers in order to collect information on the nature and level of ICT use in primary education. Further, the data were used to build statistical models that explain this ICT use in terms of predicting teacher- and school-level conditions (see Figure 1). This corresponds with the research challenges and streams of the ICT integration literature mentioned above.

The 2008 dataset contains information on 471 primary school teachers who teach in grades 1-6 from 62 schools in Flanders. The 2011 dataset contains information on 433 primary school teachers from 53 Flemish schools. These schools were different from the 2008 dataset. The two datasets were representative of the Flemish school context, meaning that they were representative of province and educational network or umbrella organization (subsidized private [Catholic] schools, subsidized public schools and community schools). Teachers' data in dataset 1 were collected from female teachers $(78 \%)$ with an average age of 38 (range 22-61). Dataset 2 contains data of $85 \%$ female teachers with an average age of 39 (range 22-61). 


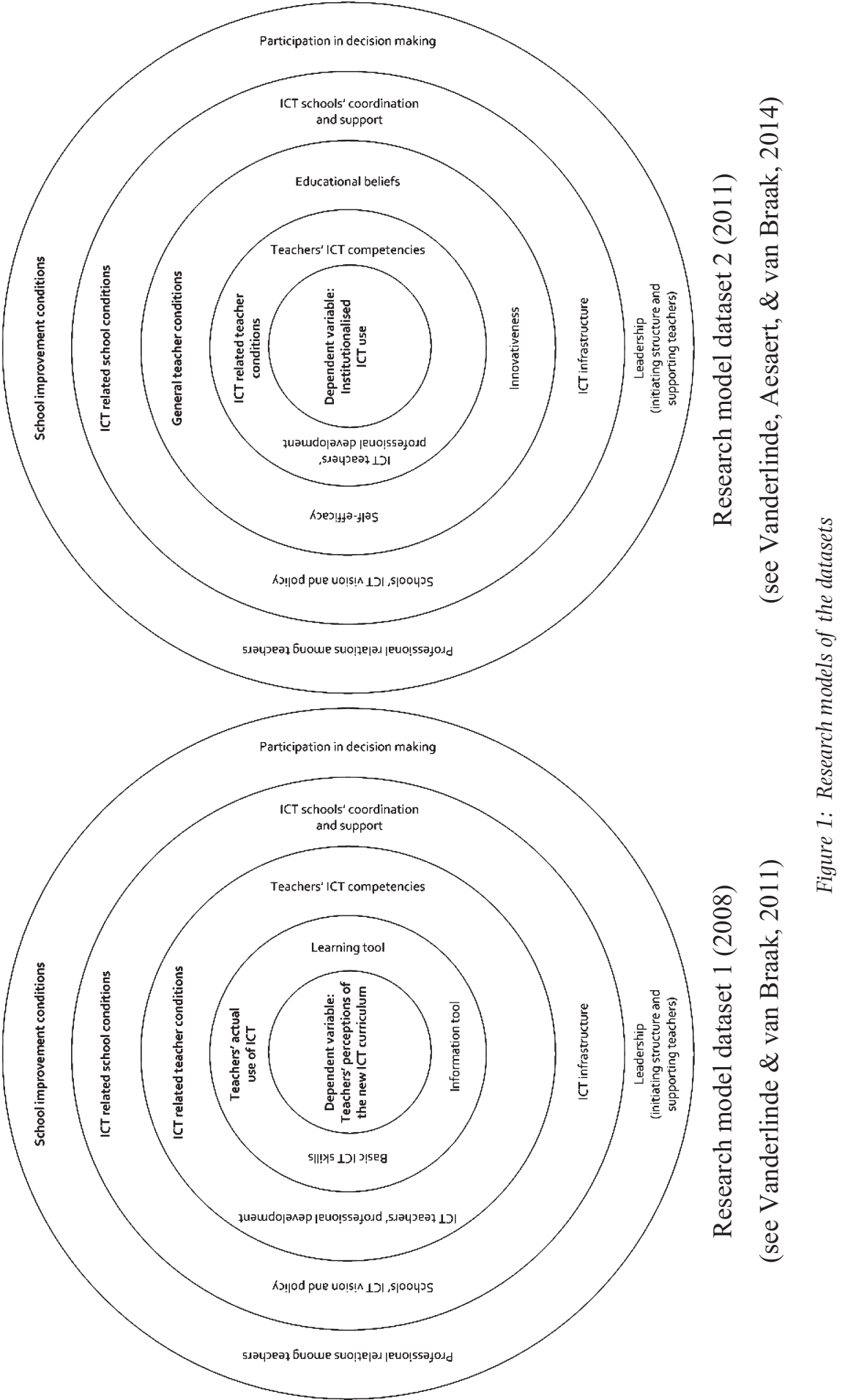




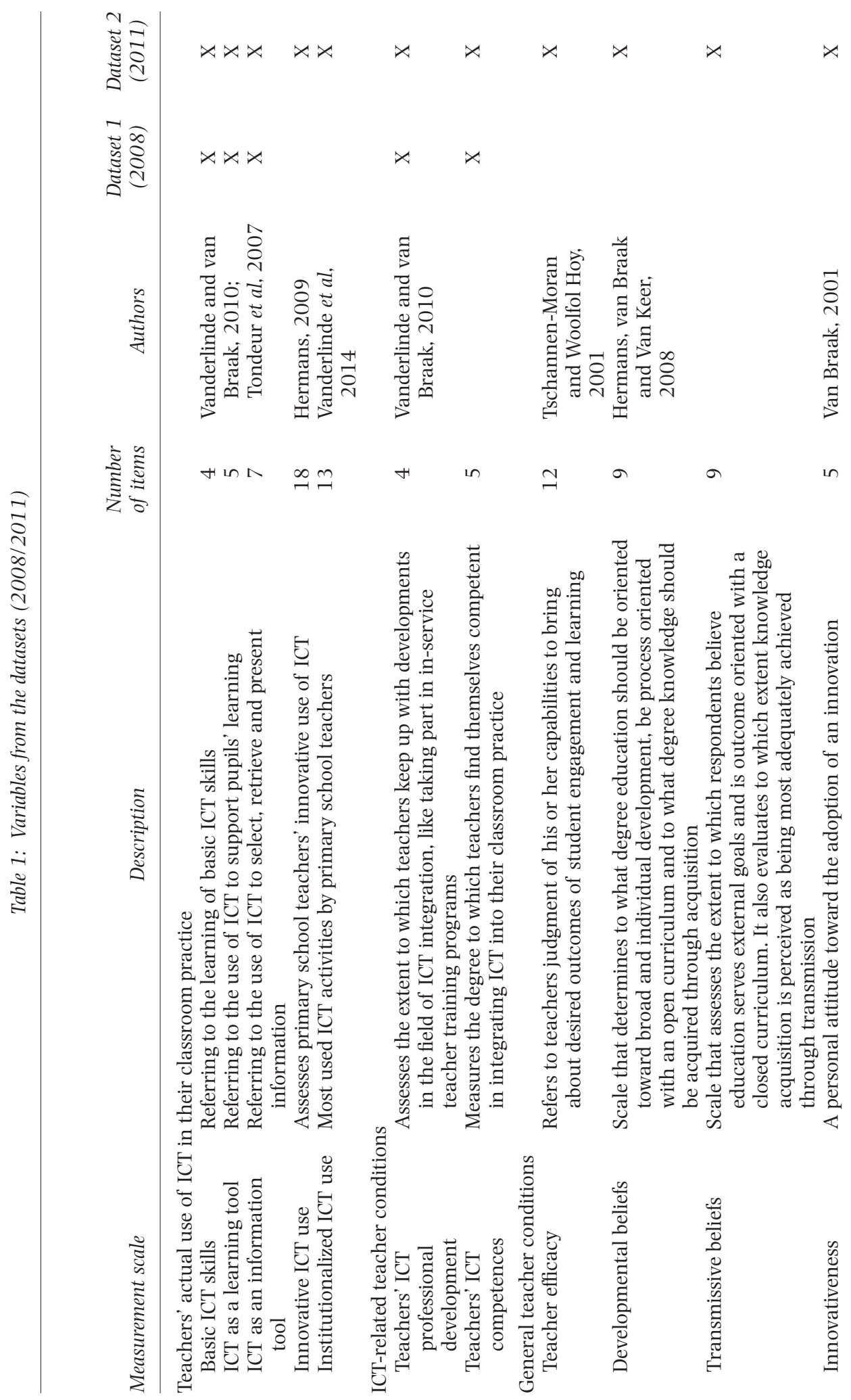




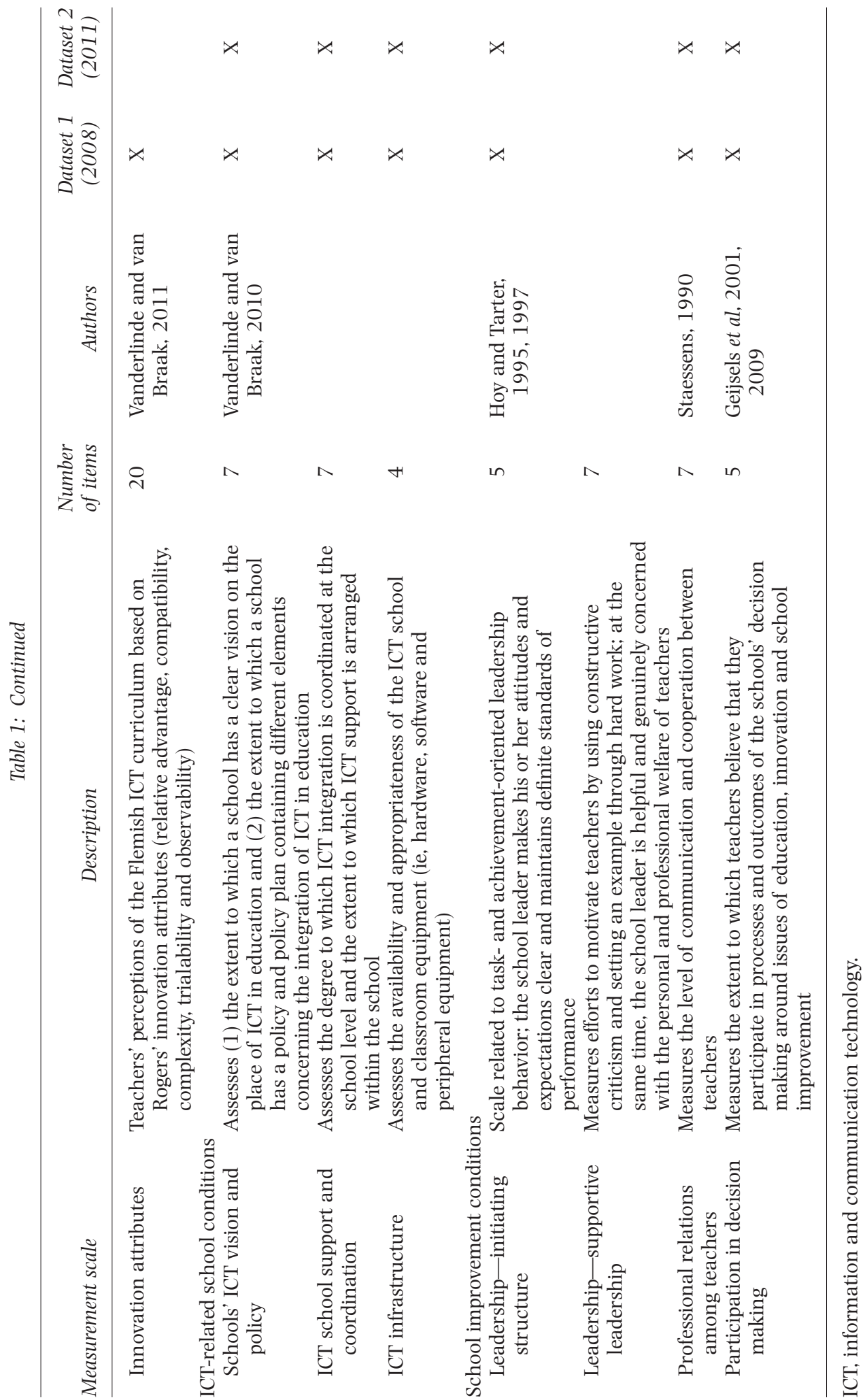


All data presented in the 2008 and 2011 dataset are based on teacher questionnaires. More specifically, the datasets contain self-reported measurements on ICT use and influencing teacherand school-level conditions. Figure 1 presents the research models of both datasets. Both figures show that the research model of the datasets builds on the e-capacity model of Vanderlinde and van Braak (2010). The e-capacity model was developed from a school improvement perspective, and consists of factors and conditions fostering the integration of ICT into teaching and learning practices. Central to this framework is the e-capacity of a school, ie, the schools' ability to create and optimize school- and teacher-level factors and conditions to bring about effective ICT change. These factors have been translated into reliable and valid measurement scales (see Vanderlinde \& van Braak, 2010) and are clustered into mediating subsets of variables (that were included in the datasets presented in this paper). For the 2008 dataset, these mediating subsets of variables refer to ICT use, ICT-related teacher conditions, ICT-related teacher-school conditions and school improvement conditions. For the 2011 dataset, an extra layer including general teacher conditions has been added to meet a major shortcoming of the 2008 dataset as this dataset does not contain any general teacher-level conditions. This extra layer contains general and teacherrelated psychological factors influencing the implementation of innovations and is similar to the general school improvement conditions. For both datasets, the subsets of variables illustrate the multilayered nature of conditions affecting ICT integration and the focus on ICT-specific conditions as well as general school improvement conditions. These influencing layers are conceived as the independent variables in both studies.

The dependent variable of dataset 1 refers to "teacher perceptions of the ICT curriculum," further operationalized as "teachers' innovation attributes of the new ICT curriculum” (Vanderlinde \& van Braak, 2011). This variable was constructed as a one-dimensional variable assessing teachers' perceptions of the new Flemish ICT curriculum based on Rogers' five innovation attributes. This variable was constructed for the "initiation" phase of the ICT curriculum as numerous authors (eg, Fullan, 2001; Vanderlinde \& van Braak, 2011) emphasize the need to investigate the perceptions of important users concerning the use of technological innovations in education. The dependent variable of dataset 2 refers to "institutionalized ICT use" (Vanderlinde et al, 2014). This is also a newly constructed variable based on existing ICT use variables (basic ICT skills, ICT as a learning tool, ICT as an information tool and innovative ICT use). Institutionalized ICT use solely pays attention to ways of ICT use that are frequently used by teachers in their classrooms. The focus on this scale is consistent with our focus on the "implementation" and "institutionalization" phase of the 2011 dataset, and it would not be possible for the 2008 dataset as this study was conceived in the "initiation" phase of the ICT curriculum.

The translation of the two research models into concrete variables is also presented in Table 1 . This table contains all variables that are included in the 2008 and 2011 dataset, together with a description of the variables including a reference to the authors that developed the variable and the number of items. All measurement instruments have been validated and are easily accessible when accessing the original papers.

Dataset 1 has been used to construct several measurement instruments necessary for the development of the e-capacity framework (Vanderlinde \& van Braak, 2010). The dataset has also been used to measure teacher innovation attributes of the Flemish ICT curriculum and to construct a hierarchical regression model (Vanderlinde \& van Braak, 2010). The 2011 dataset has been used to build a multilevel model (Vanderlinde et al, 2014) with "institutionalized ICT use" as the dependent variable and the e-capacity conditions as independent variables.

\section{Location}

All data in the dataset were made anonymous and are made available via the Ghent University Academic Bibliography. Dataset 1 is linked with the publication on teachers' innovation attrib- 
utes and can be downloaded via https://biblio.ugent.be/publication/1246549. Dataset 2 is linked with the publication that reports on the multilevel analysis conducted on the dataset and published in Computers \& Education (Vanderlinde et al, 2014). This dataset can be downloaded via https://biblio.ugent.be/publication/4251143. Both datasets are stored as SPSS files. The datasets contain the individual items (marked with capitals in the SPSS files) as well as the constructed scales (marked as "s_NAME") presented in Table 1.

\section{Restrictions}

Both datasets presented in this data paper are the intellectual property of the first author of this data paper. Dataset 1 has been gathered with financial support of the Ghent University. The research studies based on dataset 2 are funded by the Research Foundation Flanders (FWO Flanders). Datasets are made public via the Ghent University Academic Bibliography after sending an e-mail to the first author. This e-mail should contain information on the kind of analysis researchers want to conduct on the datasets. The publication of data papers and issues of data sharing are at the heart of an actual debate among academics in Flanders at the moment, and several questions need to be first explored and solved before making research data freely accessible. These questions deal with (1) ethical issues (eg, making sure that the anonymity of participants is guaranteed), (2) juridical issues (eg, questions of intellectual property) and (3) practical issues (eg, software platforms for data sharing).

\section{Conclusion}

This data paper presents two datasets consisting of data conducted with Flemish primary school teachers. Both datasets contain measurements on ICT use in primary schools on the one hand and influencing conditions on the other hand. Both datasets add to the literature on ICT use as they offer insight into the multilayered nature of conditions affecting ICT use on the one hand, and as they present data based on conceptual models that also contain validated measurement instruments on the other hand. Although some analyses have already been conducted on the datasets, new possibilities of exploring both datasets are still possible. For instance, investigating interactions between factors at different levels could further unravel the contribution of certain teacher- and school-level characteristics to teachers' ICT use. For example, it can be expected that the effect of a school's policy on the use of ICT is different for teachers having high and teachers having low ICT competences. Further, the dimensionality of teachers' ICT use could further be explored. For example, it would be interesting to use some confirmatory measurement models and investigate whether a general factor exists that reflects what is common among all the ICT use items, ie, whether a general latent factor can be identified that explains item variance that is not accounted for by the already identified dimensions of ICT use for basic skills, as an information tool and as a learning tool. This data paper at the same time illustrates the difficulties researchers are dealing with for the moment in making their datasets freely accessible. Researchers are asking for concrete and clear guidelines regarding the ethical, juridical and practical issues in order to progress publication of data papers.

\section{References}

Aesaert, K., Vanderlinde, R., Tondeur, J. \& van Braak, J. (2013). About the content of educational technology curricula: a cross-curricular state of the art. Educational Technology Research \& Development, 61, 131-151.

Anderson, R. E. (2008). Implications of the information and knowledge society for education. In J. Voogt \& G. Knezek (Eds), International handbook of information technology in primary and secondary education (pp. 5-22). New York: Springer.

Evers, M., Sinnaeve, I., Clarebout, G., van Braak, J. \& Elen, J. (2009). MICTIVO. Monitoring ICT in het Vlaamse onderwijs. [Eindrapport van het OBPWO-project 06.05]. Gent/Leuven: UGent/KULeuven.

Fullan, M. (2001). The new meaning of educational change. New York and London: Teachers College Press. 
Geijsels, F., Sleegers, P., Stoek, R. D. \& Krüger, M. L. (2009). The effect of teacher psychological school organizational and leadership factors on teachers' professional learning in schools. The Elementary School Journal, 109, 406-427.

Geijsels, F., Sleegers, P., Van den Berg, R. \& Kelchtermans, G. (2001). Conditions fostering the implementation of large-scale innovation programs in schools: teachers' perspectives. Educational Administration Quarterly, 37, 130-166.

Hermans, R. (2009). The influence of educational beliefs on the use of ICT as an educational innovation in primary education [PhD thesis]. Ghent: Ghent University, Department of Educational Studies.

Hermans, R., van Braak, J. \& Van Keer, H. (2008). Development of the beliefs about primary education scale: distinguishing a developmental and transmissive dimension. Teaching and Teacher Education, 24, 127-139.

Hew, K. F. \& Brush, T. (2007). Integrating technology into K-12 teaching and learning: current knowledge gaps and recommendations for future research. Educational Technology Research and Development, 55, $223-253$.

Hopkins, D. (2001). School improvement for real. London: RoutledgeFalmer.

Hoy, W. \& Tarter, C. J. (1995). Administrators solving the problems of practice: decision-making cases, concepts and consequences. Boston: Allyn \& Bacon.

Hoy, W. \& Tarter, C. J. (1997). The road to open and healthy schools: a handbook for change. Thousand Oaks: Corwinn Press.

de Koster, S., Kuiper, E. \& Volman, M. (2012). Concept-guided development of ICT use in 'traditional' and 'innovative' primary schools: what types of ICT use do schools develop? Journal of Computer Assisted Learning, 28, 454-464.

Kozma, R. (2008). Comparative analysis of policies for ICT in education. In J. Voogt \& G. Knezek (Eds), International handbook of information technology in primary and secondary education (pp. 1083-1096). New York: Springer.

Marshall, G. \& Cox, M. (2008). Research methods: their design, applicability and reliability. In J. Voogt \& G. Knezek (Eds), International handbook of information technology in primary and secondary education (pp. 983-1002). New York: Springer.

Staessens, K. (1990). The professional culture of primary schools in innovation: each school has its story. Leuven: Universitaire Pers.

Tondeur, J., van Braak, J. \& Valcke, M. (2007). Towards a typology of computer use in primary education. Journal of Computer Assisted Learning, 23, 197-206.

Tschannen-Moran, M. \& Woolfol Hoy, A. (2001). Measurement of teacher sense of efficacy. Teaching and Teacher Education, 17, 783-805.

Van Braak, J. (2001). Individual characteristics influencing teachers' class use of computers. Journal of Educational Computing Research, 25, 141-157.

Vanderlinde, R. \& van Braak, J. (2010). The e-capacity of primary schools: development of a conceptual model and scale construction from a school improvement perspective. Computers $\&$ Education, 55, 541553.

Vanderlinde, R. \& van Braak, J. (2011). A new ICT curriculum for primary education in Flanders: defining and predicting teachers' perceptions of innovation attributes. Educational Technology \& Society, 14, 124 135.

Vanderlinde, R., Aesaert, K. \& van Braak, J. (2014). Institutionalised ICT use in primary education: a multilevel analysis. Computers \& Education, 72, 1-10.

Vanderlinde, R., van Braak, J. \& Hermans, R. (2009). Educational technology on a turning point: curriculum implementation in Flanders and challenges for schools. ETR\&D Educational Technology Research and Development, 57, 573-584.

Voogt, J. \& Pareja Roblin, N. (2012). A comparative analysis of international frameworks for 21 century competences: implications for national curriculum policies. Journal Of Curriculum Studies, 44, 299-321. 